\title{
Tumor-associated macrophages in oral premalignant lesions coexpress CD163 and STAT1 in a Th1-dominated microenvironment
}

\author{
Kazumasa Mori ${ }^{1 \dagger}$, Shigeki Haraguchi ${ }^{1 \dagger}$, Miki Hiori ${ }^{2}$, Jun Shimada ${ }^{1}$ and Yoshihiro Ohmori ${ }^{2 *}$
}

\begin{abstract}
Background: Tumor-associated macrophages (TAMs) are implicated in the growth, invasion and metastasis of various solid tumors. However, the phenotype of TAMs in premalignant lesions of solid tumors has not been clarified. In the present study, we identify the phenotype of TAMs in leukoplakia, an oral premalignant lesion, by immunohistochemical analysis and investigate the involvement of infiltrated T cells that participate in the polarization of TAMs.
\end{abstract}

Methods: The subjects included 30 patients with oral leukoplakia and 10 individuals with normal mucosa. Hematoxylin and eosin slides were examined for the histological grades, and immunohistochemical analysis was carried out using antibodies against CD68 (pan-MФ), CD80 (M1 MФ), CD163 (M2 MФ), CD4 (helper T cells: Th), CD8 (cytotoxic T cells), CXCR3, CCR5 (Th1), CCR4 (Th2), signal transducer and activator of transcription (STAT1), phosphorylated STAT1 (pSTAT1) and chemokine CXCL9. The differences in the numbers of positively stained cells among the different histological grades were tested for statistical significance using the Kruskal-Wallis test. Correlations between different types of immune cells were determined using Spearman's rank analysis.

Results: An increase in the rate of $\mathrm{CD}_{163^{+}} \mathrm{TAM}$ infiltration was observed in mild and moderate epithelial dysplasia, which positively correlated with the rate of intraepithelial $\mathrm{CD}^{+}$Th cell infiltration. Although $\mathrm{CCR}^{+}$cells rarely infiltrated, $\mathrm{CXCR3^{+ }}$ and $\mathrm{CCR} 5^{+}$cells were observed in these lesions. Cells positive for STAT1 and chemokine CXCL9, interferon- (IFN)-induced gene products, and PSTAT1 were also observed in the same lesions. Double immunofluorescence staining demonstrated that the cells that were positive for CD163 were also positive for STAT1.

Conclusions: CD163 ${ }^{+}$TAMs in oral premalignant lesions coexpress CD163 and STAT1, suggesting that the TAMs in oral premalignant lesions possess an M1 phenotype in a Th1-dominated micromilieu.

\section{Background}

Oral squamous cell carcinoma (OSCC), which accounts for approximately $2 \%$ of total new cancer cases, is the most common type of oral cancer [1]. Despite recent advances in our understanding and in the treatment of other types of cancer, the five-year survival rate after diagnosis of OSCC remains low at approximately $50-60 \%$ [2]. The survival rate of patients with early-

\footnotetext{
*Correspondence: ohmori@dent.meikai.ac.jp

${ }^{\dagger}$ Equal contributors

${ }^{2}$ Division of Microbiology and Immunology, Department of Oral Biology and Tissue Engineering, Meikai University of School of Dentistry, 1-1 Keyakidai,

Sakado, Saitama 350-0283, Japan

Full list of author information is available at the end of the article
}

stage OSCC is higher than that of advanced patients, exceeding $70 \%$ [3]. Therefore, early detection of OSCC is indispensable for improving prognosis.

Oral leukoplakia is a premalignant lesion of the oral mucosa that is characterized by a circumscribed thickening of the mucosa covered by whitish patches [4]. Although hospital-based follow-up studies have shown that between $<1 \%$ and $18 \%$ of oral premalignant lesions will develop into oral cancer, a certain clinical subtype of leukoplakia with epithelial dysplasia has been shown to be at an increased risk for malignant transformation [5]. However, histological assessment of epithelial dysplasia has also demonstrated that not all lesions that show dysplasia will develop into oral cancer, and some will 
even regress [5]. Therefore, the development of other methods for predicting the malignant potential of premalignant lesions has been proposed. Recent studies have examined the molecular profiles of oral premalignant lesions in terms of the risk for malignant transformation [6]. Genetic alterations and molecular abnormalities have been identified in oral premalignant lesions. A loss of heterozygosity $(\mathrm{LOH})$ at chromosome $9 p$ and $3 p$ and the absence of p19, a tumor-suppressor protein, are frequently observed in oral premalignant lesions $[7,8]$.

Although genetic alterations in epithelial cells are essential for the development of premalignant lesions, recent studies have shown that the nature of the tumor microenvironment and circumjacent stromal cells, including infiltrated immune cells, can significantly modify the outcome of these alterations $[9,10]$. Numerous studies have demonstrated that tumor-associated macrophages (TAMs) initiate and promote tumorigenesis in many types of solid tumors [11-13], and a strong correlation between an abundance of TAMs and poor prognosis has been demonstrated in breast, prostate, cervical, and bladder cancers [11]. However, contrary to their tumor promoting function, TAMs that infiltrated colon and lung cancers have been associated with a better prognosis in patients [14-18]. Analysis of the phenotypes of the infiltrated TAMs revealed that the TAMs involved in poor patient prognosis share many common features with alternatively activated macrophages or M2 macrophages, which express high levels of the scavenger receptors CD163 and CD204, high levels of the chemokines CCL17, CCL22 and CCL24, and low levels of IL-12 [12, 19]. In contrast to alternatively activated macrophages, the TAMs associated with a better patient prognosis share a phenotype with classically activated macrophages or M1 macrophages, which express HLA$\mathrm{DR}$, inducible nitric oxide synthase (iNOS), and tumor necrosis factor- $\alpha$ (TNF- $\alpha)[17,18]$. These lines of evidence indicate that the functional competence of macrophages is heterogeneous and that the functional properties are acquired and modified in response to changes in the tumor microenvironment [12,13].

Previous studies have observed the increased infiltration of mononuclear cells in oral premalignant lesions and OSCC [20-24]. We and others have previously observed an increased number of TAMs during the progression of OSCC, and this number positively correlates with the histopathological grade of OSCC and poor prognosis in OSCC patients [25-29]. These results suggest that TAMs participate in the progression and development of OSCC. Although the phenotypes of TAMs in various types of solid tumors have been extensively characterized, the phenotypes and functional properties of the TAMs that infiltrate premalignant lesions of solid tumors remain to be determined. This study aimed to examine TAM density in oral leukoplakia, a premalignant lesion of the oral cavity, and to characterize the macrophage phenotype (M1 or M2). We also investigated the involvement of infiltrated $\mathrm{T}$ cells that contribute to the induction of macrophage phenotypes.

\section{Methods}

\section{Tissue specimens}

Biopsy specimens were obtained from patients treated at the Division of Oral and Maxillofacial Surgery, Meikai University School of Dentistry. A total of 30 specimens diagnosed as oral leukoplakia were used in this study, and the clinicopathological characteristics of the patients examined in this study are listed in Table 1. Median age at the time of diagnosis was 61.0 years old, and 20 of the 30 patients were men. The most frequently affected site was the gingiva ( $43.3 \%)$, followed by the buccal mucosa (26.7 \%), tongue (13.3\%), palate (10\%), and lip (6.7 \%). Biopsy specimens (seven from the tongue, two from the gingiva, and one from the palate) diagnosed as normal oral mucosa were used as controls. The current study was reviewed and approved by the Research Ethics Committee of Meikai University School of Dentistry (reference \#: A0290), and written informed consent for participation in this study was obtained from the

Table 1 Clinicopathological characteristics of the patients with oral precancerous lesions

\begin{tabular}{ll}
\hline Clinical variables & $\%(\mathrm{n})$ \\
\hline Age & \\
\hdashline 60 & $33.3(10)$ \\
$\geqq 60$ & $66.7(20)$ \\
Mean & 61.0 years \\
Gender & \\
Male & $66.7(20)$ \\
Female & $33.3(10)$ \\
Region & \\
Gingiva & $43.3(13)$ \\
Buccal mucosa & $26.7(8)$ \\
Tongue & $13.3(4)$ \\
Palate & $10.0(3)$ \\
Lip & $6.7(2)$ \\
Histological grade & \\
Without dysplasia & $16.7(5)$ \\
Mild & $23.3(7)$ \\
Mild to moderate & $16.7(5)$ \\
Moderate & $16.7(5)$ \\
Moderate to severe & $13.3(4)$ \\
Severe & $13.3(4)$ \\
\hline
\end{tabular}


patients. These tissues were fixed for $24-48 \mathrm{~h}$ in $4 \%$ formaldehyde freshly prepared from paraformaldehyde in phosphate-buffered saline (PBS) at $4{ }^{\circ} \mathrm{C}$. The tissue specimens were sliced into 4- $\mu \mathrm{m}$ sections and mounted onto 3-aminopropyltriethoxysilane-coated glass slides. Three oral pathologists independently examined the hematoxylin and eosin slides and re-evaluated the histological diagnosis based on the WHO Classification of Head and Neck Tumors [30]. When the diagnoses were not in agreement, the biopsy specimen was re-examined and discussed until a consensus was reached.

\section{Immunohistochemical staining}

The tissue sections were deparaffinized, immersed in $10 \mathrm{mM}$ citrate buffer ( $\mathrm{pH}$ 6.0) and heated in a microwave oven for 15 min for antigen retrieval. For CD68 antigen retrieval, the tissue sections were treated with proteinase K (20 $\mu \mathrm{g} / \mathrm{ml}$, Roche Diagnostics, Basel, Switzerland) at room temperature for $15 \mathrm{~min}$. After rinsing in PBS, the sections were incubated with $3 \%$ hydrogen peroxide in methanol for 10 min to block endogenous peroxidase activity. Endogenous avidin and biotin were blocked using the Avidin/Biotin Blocking Kit (Zymed Laboratories, San Francisco, CA, USA) at room temperature for $10 \mathrm{~min}$. To reduce nonspecific antibody binding, the samples were exposed to $2 \%$ bovine serum albumin (BSA) for $30 \mathrm{~min}$. A list of the primary antibodies used in this study is shown in Table 2. Tissue sections were incubated with primary antibody at $4{ }^{\circ} \mathrm{C}$ in a humidified chamber overnight. Then, the tissue sections were washed in PBS and incubated with horseradish peroxidase-labeled anti-mouse or antirabbit antibodies (Dako EnVision System, HRP-Labeled Polymer, Dako, Kyoto, Japan) for $30 \mathrm{~min}$. Peroxidase activity was visualized by immersion of the tissue sections using the AEC Substrate Kit (Dako), which produced a brown reaction product. Finally, the tissue sections were counterstained with Mayer's hematoxylin and mounted. As a negative control, the primary antibody was replaced with $2 \%$ BSA.

To evaluate the positively stained cells after incubation with each antibody, three high-power magnification fields $(200 \times)$ with the most abundant distribution of positive cells were selected from each specimen. The numbers of positively stained and unstained cells were counted. The data are expressed as the mean percentage of the ratio of the number of positive cells relative to the total number of cells.

\section{Double-labeled fluorescent immunostaining}

The tissue sections were deparaffinized and immersed in Tris-HCl buffered saline (TBS: $\mathrm{pH}$ 7.4) supplemented with $0.5 \%$ Triton-X 100 (Bio-Rad Laboratories, Hercules, CA, USA) and $3 \% \mathrm{H}_{2} \mathrm{O}_{2}$ at room temperature for $60 \mathrm{~min}$. All sections were pre-blocked in $10 \%$ non-immune goat serum (Zymed) for $1 \mathrm{~h}$ at room temperature to reduce nonspecific antibody binding. After being rinsed in PBS, the tissue sections were incubated with mouse antihuman CD163 monoclonal antibody (1:100 dilution) and rabbit anti-human STAT1 polyclonal antibody (1:500) or rabbit anti-phosphorylated (Try701) STAT1 monoclonal antibody (1:200) for $60 \mathrm{~min}$ at room temperature. The tissue sections were subsequently incubated with Alexa Fluor 488 goat anti-mouse IgG antibody at 1:2000 (Life Technologies, Carlsbad, CA, USA) and Alexa Fluor 546 goat anti-rabbit IgG antibody at 1:2000 (Life Technologies) for $60 \mathrm{~min}$ at room temperature. The sections were again washed in TBS prior to being cover-slipped with anti-fade mounting medium (ProLong Antifade Kit, Life Technologies). The primary antibodies were omitted in the control experiments to verify the absence of secondary antibody binding. The stained slides were viewed on a

Table 2 Primary antibodies used in this study

\begin{tabular}{|c|c|c|c|c|}
\hline Antigen & Marker & Antibody & Dilution & Vendor \\
\hline CD68 & Pan-MФ & Mouse anti-hCD68 Mab & $1: 80$ & Dako, Glostrup, Denmark \\
\hline CD80 & M1 MФ & Mouse anti-hCD80 Mab & $1: 200$ & R\&D systems, Minneapolis, MN, USA \\
\hline CD163 & M2 MФ & Mouse anti-hCD163 Mab & $1: 200$ & Leica, Wetzlar, Germany \\
\hline CD4 & Th & Mouse anti-hCD4 Mab & $1: 100$ & NordiQC organization, Aalborg Denmark \\
\hline CD8 & $\mathrm{CTL}$ & Mouse anti-hCD8 Mab & $1: 100$ & Dako, Glostrup, Denmark \\
\hline CCR4 & Th2 & Mouse anti-hCCR4 Mab & $1: 100$ & Novus biological, Littleton, CO, USA \\
\hline CCR5 & Th1 & Rabbit anti-hCCR5 pab & $1: 200$ & Abcam, Cambridge, UK \\
\hline CXCR3 & Th1 & Mouse anti-hCXCR3 Mab & $1: 200$ & R\&D systems, Minneapolis, MN, USA \\
\hline CXCL9 & Chemokine Th1 & Mouse anti-hCXCL9 Mab & $1: 200$ & R\&D systems, Minneapolis, MN, USA \\
\hline STAT1 & IFNy-inducible gene & Rabbit anti-hSTAT1 Pab & $1: 200$ & Santa Cruz, Santa Cruz, CA, USA \\
\hline Phospho-STAT1 & pSTAT1 (Tyr701) & Rabbit anti-pSTAT1 Mab & $1: 50$ & Cell signaling, Boston, MA, USA \\
\hline
\end{tabular}


laser scanning confocal microscope (TCS SP-2, Leica, Bensheim, Germany).

\section{Statistical analysis}

The significant differences in the numbers of positively stained cells among the various pathological grades were tested using the Kruskal-Wallis nonparametric test. Correlations between the various types of infiltrated immune cells were tested using nonparametric Spearman's rank analysis. Two-sided $p$ values of $<0.05$ were judged to be significant.

\section{Results}

\section{Infiltration of $\mathrm{CD}_{163^{+}}$macrophages in leukoplakia}

We examined the infiltration of macrophages for various pathological grades of leukoplakia using antibodies to CD68 [31], CD80 [12, 32], and CD163 [33]. Few cells were positively stained for these macrophage markers in the normal mucosa (Fig. 1a, d, g), while $\mathrm{CD}^{+} 8^{+}, \mathrm{CD} 80^{+}$and $\mathrm{CD}_{163}{ }^{+}$cells were observed in specimens from leukoplakia lesions $(\times 100$ : Fig. 1 b, e, $h$ and $\times 400$ : c, f, i). The majority of the infiltrated macrophages were distributed in the subepithelial stroma. Although the percentages of infiltrated $\mathrm{CD}^{+} 8^{+}$(Fig. 1j) and $\mathrm{CD} 80^{+}$(Fig. 1k) cells did not differ significantly by pathological grade, the number of infiltrated $\mathrm{CD}_{163^{+}}$cells was significantly increased in mild to moderate and mild dysplasia compared to samples without dysplasia (Fig. 11).

Because the tumor microenvironment modulates the functional properties of TAMs, we examined the infiltration of $\mathrm{T}$ cells in leukoplakia. Both $\mathrm{CD}^{+}{ }^{+}$(Fig. 2) and $\mathrm{CD}^{+}$(data not shown) $\mathrm{T}$ cells were observed in the subepithelial stroma of leukoplakia. Interestingly, a significant increase in the percentages of $\mathrm{CD}^{+} \mathrm{T}$ cells was detected in the intraepithelial lesions of moderate and severe dysplasia (Fig. 2b). Spearman's rank correlation coefficient was used to assess the potential relationship between $\mathrm{CD}_{163}{ }^{+}$macrophages and $\mathrm{CD}_{4}^{+} \mathrm{T}$ cells. The percentages of $\mathrm{CD} 163^{+}$macrophages positively correlated with the intraepithelial $\mathrm{CD}^{+} \mathrm{T}$ cells $(p<0.0009$; Fig. 2c). However, there were no significant correlations between $\mathrm{CD}^{2} 8^{+}$cells and $\mathrm{CD} 4^{+} \mathrm{T}$ cells, nor between $\mathrm{CD}^{+} 0^{+}$cells and $\mathrm{CD} 4^{+} \mathrm{T}$ cells (Fig. $2 \mathrm{~d}, \mathrm{e}$ ).

\section{Infiltration of $\mathrm{CXCR}^{+}{ }^{+} \mathrm{T}$ cells in leukoplakia and correlation with STAT $1^{+}$cells}

Th1-derived IFN reportedly induces classically activated M1 macrophages, whereas Th2-derived IL-4 and IL-13 induce alternatively activated M2 macrophages $[12,19]$. To further analyze the subset of infiltrated $\mathrm{T}$ cells that affect the phenotype of TAMs, we immunohistochemically examined the infiltrated $\mathrm{CD} 4^{+} \mathrm{T}$ cells using antibodies to chemokine receptor CXCR3 and CCR5, markers for Th1 cells, and antibodies to CCR4, a marker for Th2 cells [34]. Although CCR4 ${ }^{+} \mathrm{T}$ cells were rare in normal mucosa and in leukoplakia lesions (data not shown), CXCR3 ${ }^{+}$(Fig. 3a, b) and CCR5 ${ }^{+}$(Fig. 3c, d) T cells abundantly infiltrated the subepithelial stroma of leukoplakia. These results indicate that $\mathrm{CD}^{+}$Th1 cells are the predominant subset of $\mathrm{T}$ cells that infiltrate leukoplakia.

Because Th1 cells produce IFN, which induces M1 macrophages, we next assessed whether the IFNinducible gene products STAT1 [35] and CXCL9/Mig, a chemokine for Th1 [36], were expressed in leukoplakia (Fig. 4). STAT1 ${ }^{+}$cells were widely distributed in the subepithelial lesions of leukoplakia. The percentages of $\mathrm{CXCR}^{+}$cells positively correlated with the percentages of STAT1 ${ }^{+}$cells $(p=0.0465$; Fig. $4 \mathrm{c})$. Tyrosine-phosphorylated STAT1 (pSTAT1), an active form of STAT1, was also detected in the lesions (Fig. 4d, e), though the frequency of pSTAT1-positive cells was lower than that of STAT1-positive cells. Cells positive for the IFN-inducible chemokine CXCL9 were also observed in the subepithelial lesion of leukoplakia (Fig. 4f, g). Taken together, these results indicate that the leukoplakia lesions form a Th1-dominated microenvironment and suggest that Th1-derived IFN affects the infiltrated macrophages to polarize the M1 phenotype.

\section{Colocalization of $\mathrm{CD} 163^{+}$cells with STAT1 in leukoplakia}

To further characterize the $\mathrm{CD}_{163^{+}}$macrophages in leukoplakia, we examined the coexpression of CD163 and STAT1 or pSTAT1 using double-labeling immunofluorescence (Fig. 5). CD $163^{+}$macrophages were distributed in the subepithelial lesion, and the majority of $\mathrm{CD}_{163}{ }^{+}$cells located in the papillary dermis colocalized with STAT1 (Fig. 5a). The percentages of $\mathrm{CD}_{163}{ }^{+}$macrophages and $\mathrm{STAT}^{+}$cells were positively correlated $(p=0.0034 ;$ Fig. $5 \mathrm{~b})$. Although the percentages of single-stained cells for CD163 and STAT1 were $16.4 \%$ and $32.1 \%$, respectively, the percentage of double-stained cells was $51.5 \%(n=4)$. The $\mathrm{CD}_{163^{+}}$cells also coexpressed pSTAT1 (Fig. 5c). These results indicate that $\mathrm{CD} 163^{+}$macrophages in oral leukoplakia coexpress active STAT1 and suggest that the $\mathrm{CD}_{163^{+}}$macrophages possess an M1 phenotype in a Th1-dominated microenvironment.

\section{Discussion}

Macrophages are one of the major cellular components in the tumor microenvironment, and macrophages have been considered to be crucial to tumor development $[13,37]$. Although a number of studies have reported the phenotypes and properties of these macrophages (i.e., TAMs) in various human solid tumors, including oral squamous cell carcinoma, the phenotypes of TAMs 


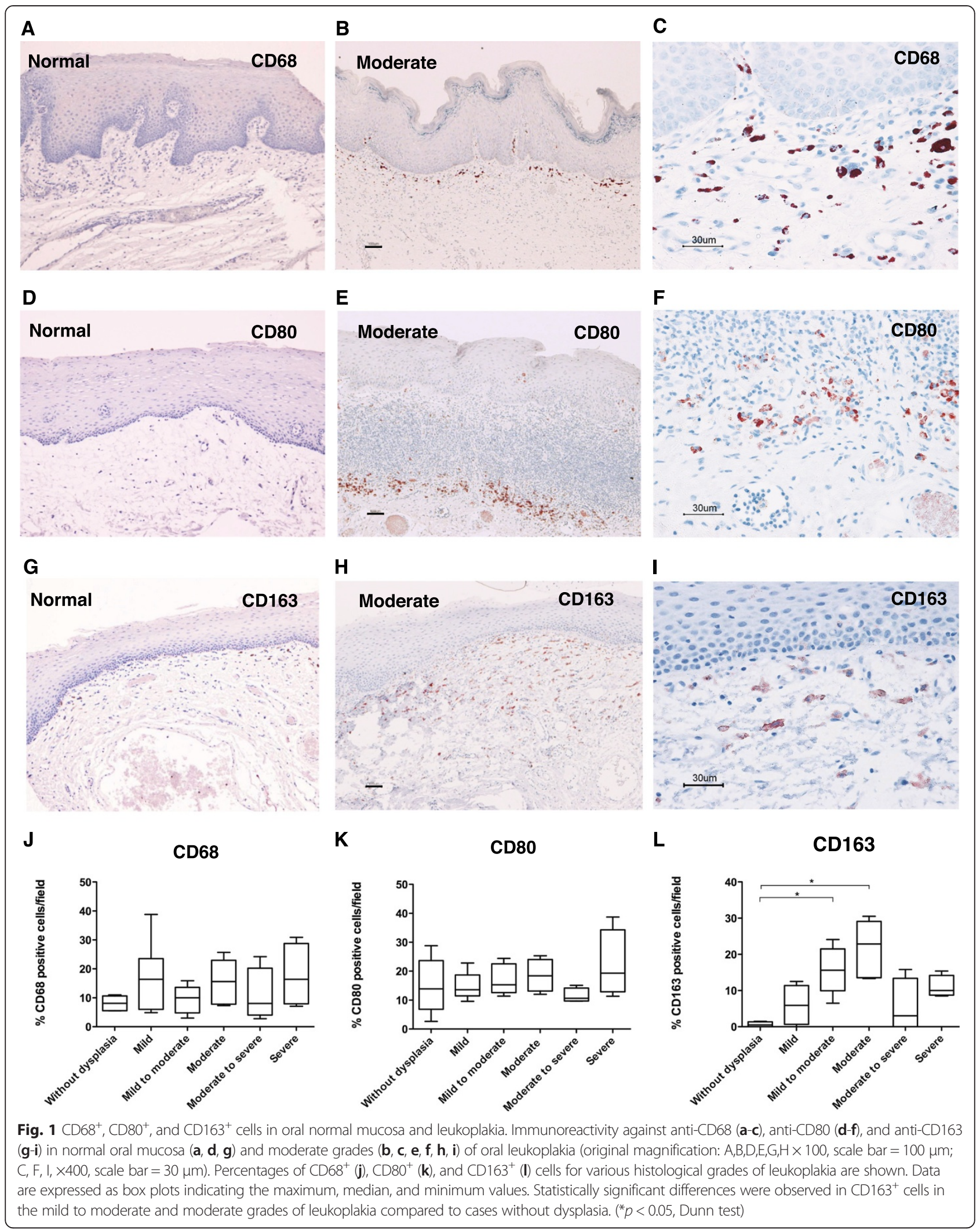




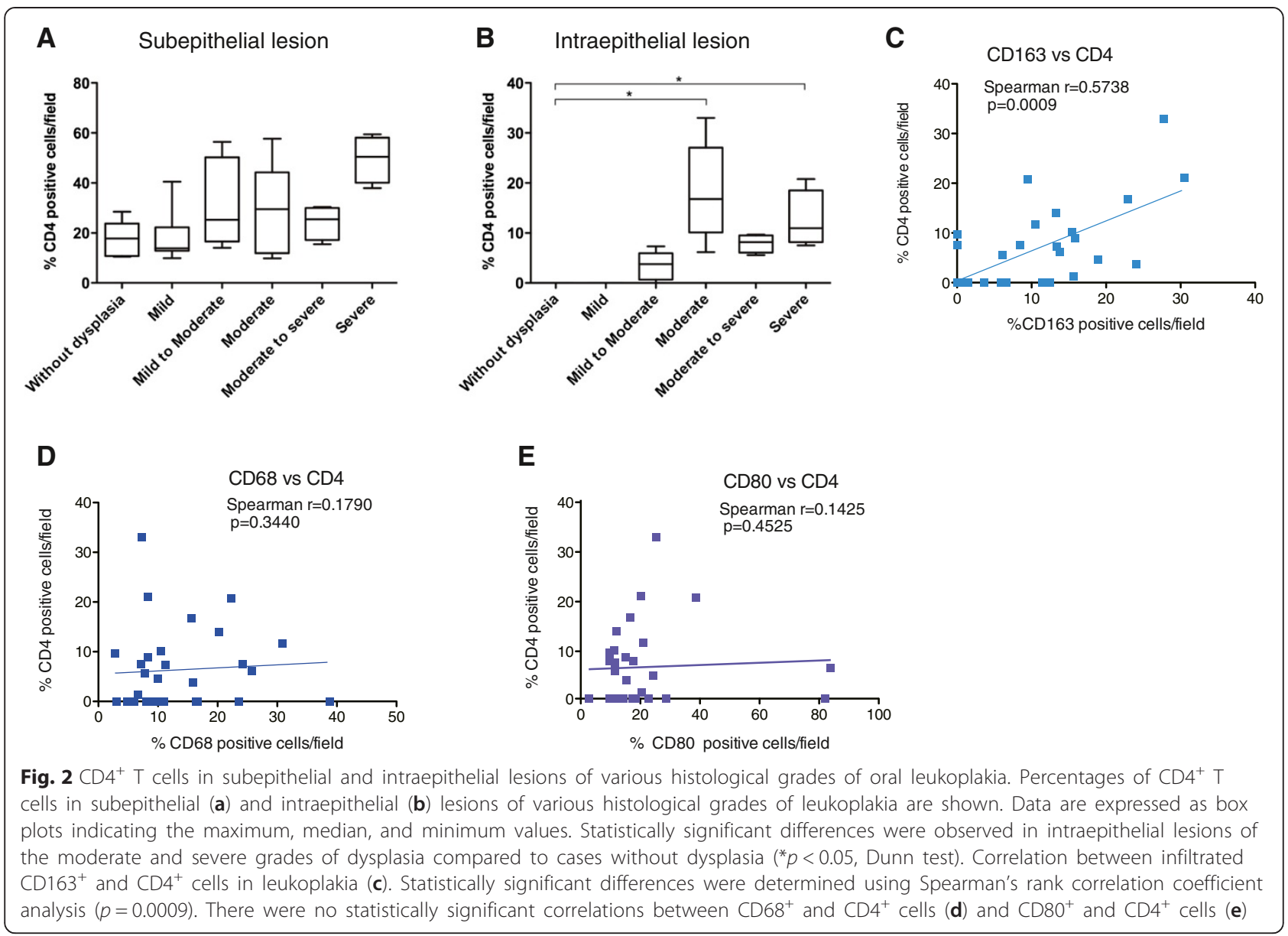

in the premalignant lesions of these solid tumors remain to be determined. Specifically, changes in the phenotypes and functional properties of TAMs in premalignant lesions during tumor development have not yet been characterized. To this end, we examined dissected specimens from 30 patients who underwent biopsy and received a diagnosis of oral leukoplakia, an oral premalignant lesion, by immunohistochemical analysis of several macrophage and $\mathrm{T}$ cell markers. The results demonstrated that although CD163 has been considered a M2 macrophage marker in many solid tumors [38-41], the $\mathrm{CD} 163^{+}$macrophages in oral leukoplakia appear to possess an M1 phenotype characterized by the expression of IFN-inducible gene products. Furthermore, infiltrated $\mathrm{CXCR}^{+}$and $\mathrm{CCR}^{+}$ Th1 cells, a major IFN-producing cell type, were also observed in the tumor microenvironment. These results suggest that the infiltrated Th1 cells, which produce IFN, affect the phenotype of $\mathrm{CD}_{16}{ }^{+}$macrophages in oral premalignant lesions.

The macrophages were classified as M1 (classically activated) and M2 (alternatively activated) macrophages based on the expression of macrophage gene products, including receptors, cytokines, and effector molecules, induced by classical macrophage-activating stimuli such as Th1derived IFN or the Th2-derived anti-inflammatory cytokines IL-4 and IL-13 [12, 19, 42]. M1 macrophages produce large amounts of pro-inflammatory cytokines, reactive oxygen intermediates and reactive nitrogen intermediates, such as nitric oxide (NO), which contribute to the anti-tumor activity of macrophages [12]. In contrast, M2 macrophages have been suggested to contribute to angiogenesis, tissue remodeling, and tumor progression by inducing the expression of mannose receptors, scavenging receptors, angiogenic factor such as vascular endothelial growth factor (VEGF), and low levels of pro-inflammatory cytokines [12]. Although the M1/M2 concept of macrophage polarization helps explain the functional properties of macrophages in various infectious and immunological diseases, recent accumulated evidence has shown that the infiltrated TAMs in human solid tumors appear to consist of a heterogeneous population [40, 43]. TAMs in human cutaneous SCC appear to consist of a mixed subpopulation of $\mathrm{CD}_{163^{+}}$cells that express M1 markers, M2 markers or both M1 and M2 markers [43]. In agreement with this previous study, we have also demonstrated that $\mathrm{CD} 163^{+}$cells express an 

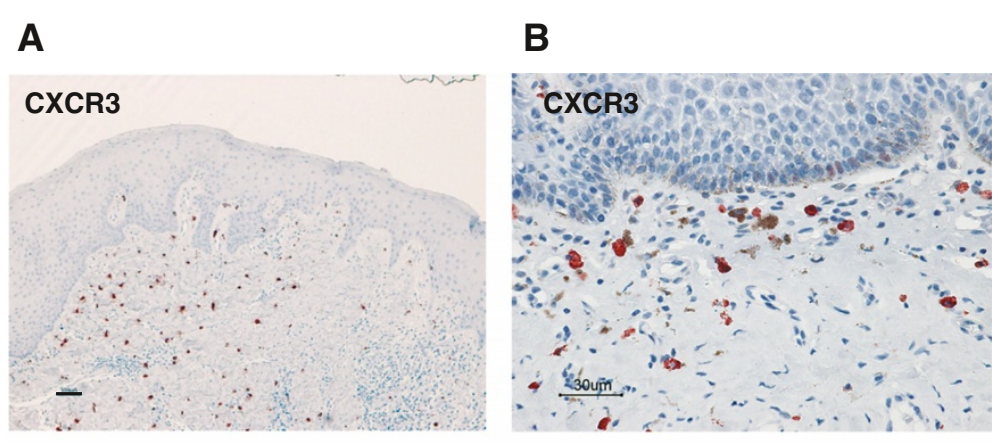

C

D
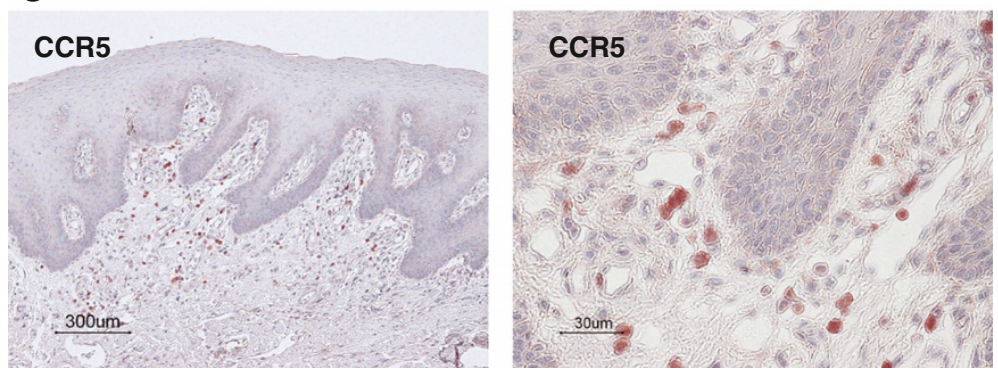

Fig. 3 Immunohistochemical staining of oral leukoplakia with the anti-CXCR3 and anti-CCR5 antibodies. Immunoreactivity against anti-CXCR3 $(\mathbf{a}, \mathbf{b})$ and anti-CCR5 $(\mathbf{c}, \mathbf{d})$ antibodies for moderate grades of oral leukoplakia (original magnification: A, C: $\times 100 ; B, D: \times 400)$. CXCR3 ${ }^{+}$and $C C R 5^{+}$ Th1 cells were mainly distributed in the subepithelial lesion. Scale bar $=100 \mu \mathrm{m}(\mathbf{a}), 300 \mu \mathrm{m}(\mathbf{c})$, and $30 \mu \mathrm{m}(\mathbf{b}, \mathbf{d})$

M1 marker in oral premalignant lesions. Related to these findings, we and others have previously reported that $\mathrm{CD}_{163^{+}}$macrophages are the major TAMs in OSCC and that an increased number of $\mathrm{CD} 163^{+}$macrophages correlates with a poor prognosis [27, 28, 44, 45]. Our preliminary double-labeling immunofluorescence data for CD163 and STAT1 shows that the CD163 ${ }^{+}$ TAMs in OSCC also coexpress STAT1. These results suggest that $\mathrm{CD}_{163}{ }^{+}$TAMs with the M1 phenotype persist in the tumor microenvironment from the premalignant to the malignant stage. The functional heterogeneity of the $\mathrm{CD}_{163}{ }^{+}$TAMs that express M1 markers in OSCC in terms of antitumor or protumor potency remains to be determined. $\mathrm{CD}_{163^{+}}$TAMs need to be further characterized to better understand the role of TAMs in the progression of OSCC.

TAMs acquire functional competence in response to various cytokines and mediators encountered within the tumor microenvironment [46]. Tumor-associated immune cells, as well as tumor cells themselves, are the major sources of mediators that affect the functional properties of TAMs. A mouse tumor model of mammary carcinomas demonstrated that IL-4-expressing $\mathrm{CD} 4^{+} \mathrm{T}$ cells indirectly promote the invasion and metastasis of mammary adenocarcinomas by promoting the protumor function of TAMs [47]. The importance of Th2 cytokines, including IL-4, IL-10, and IL-13, in the regulation of the protumor functions of TAMs has also been demonstrated in human lung adenocarcinomas $[40,48]$. However, the role of infiltrated $\mathrm{T}$ cells in the polarization of TAMs in premalignant lesions of human solid tumors is not completely understood. In the present study, we evaluated the relationship between infiltrated $\mathrm{T}$ cells and the polarization of TAMs in oral leukoplakia and found a positive correlation between the numbers of $\mathrm{CD} 4^{+} \mathrm{T}$ cells and $\mathrm{CD} 163^{+}$macrophages. Intriguingly, the infiltrated $\mathrm{CD} 4^{+} \mathrm{T}$ cells in oral leukoplakia consisted of $\mathrm{CXCR}^{+}$and $\mathrm{CCR}^{+}$Th1 cells, a major IFN-producing cell type, and CCR4 ${ }^{+}$Th2 cells were rare in the lesion. Consistent with the increased infiltration of Th1 cells and STAT $1^{+}$cells, the expression of an IFN-inducible gene product [35] was also increased in the lesion. These results suggest that the tumor microenvironment of oral leukoplakia creates a Th1-dominated microenvironment that polarizes TAMs toward the M1 phenotype. Our double-labeled immunofluorescence analysis demonstrated that $\mathrm{CD}_{163}{ }^{+}$macrophages coexpressed active STAT1 (pSTAT1). Thus, it is highly likely that the infiltrated Th1 cells modulate the phenotype of TAMs in oral premalignant lesions.

The recruitment of $\mathrm{CXCR}^{+}$Th1 cells is mediated by IFN-inducible chemokines such as CXCL9 and CXCL10 [49], which are produced by a variety of cell types, including epithelial cells, fibroblasts, and macrophages, in response to IFNs [50, 51]. IFNs and TNF or CD40 ligand synergistically induce the expression 


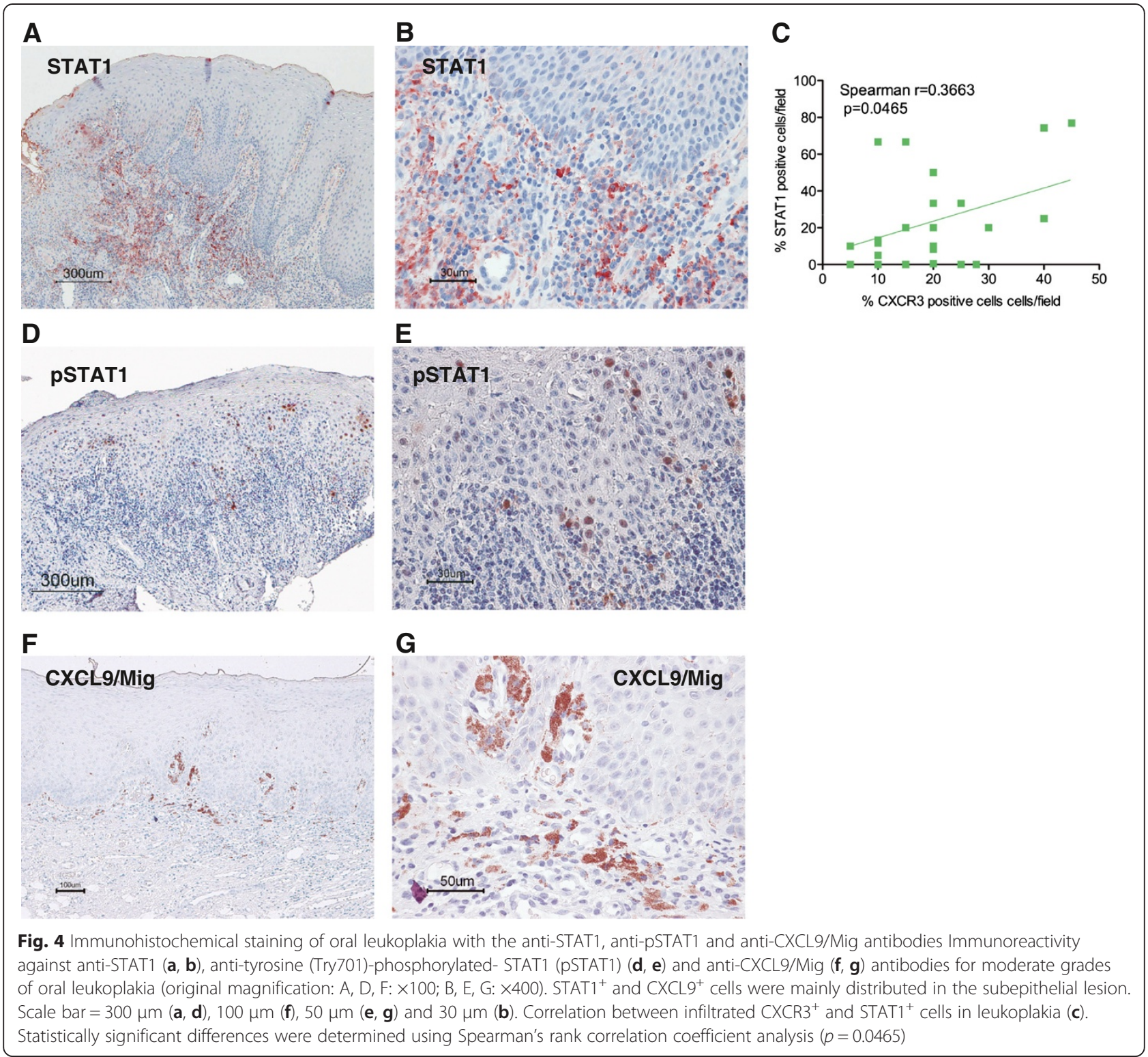

of these chemokines [52, 53]. Although the initial triggering molecules that induce these chemokines are unknown, epithelial cells in the dysplastic lesion, which are continuously stimulated by carcinogens and are genetically altered, may produce these chemokines. In fact, our immunohistochemical analysis demonstrated that CXCL9 was present in the subepithelial lesion of leukoplakia. After the recruitment of $\mathrm{CXCR}^{+}$ Th1 cells, the secretion of IFN could further skew the oral premalignant lesions toward a Th1-dominated microenvironment. Intriguingly, a previous proteomic analysis of OSCC revealed that the IFN signaling pathway is significantly enhanced in OSCC lesions and that the expression of IFN-inducible gene products, including STAT1, was up-regulated [54]. Taken together, these results suggest that the persistent IFN-stimulating environment from the premalignant to malignant lesion may allow tumor cells to acquire resistance to the antitumor responses of IFNs via cancer immunoediting [55]. IFN-induced M1 macrophages have been shown to act as important effectors during cancer immunoediting in a mouse tumor model [56]. Further in vivo studies using animal models of OSCC are needed to explore the functional role of IFN-stimulated M1 macrophages in the progression of malignant transformation.

We histopathologically graded the biopsy specimens of oral leukoplakia based on the WHO classification [30] and explored the relationship between the histological grading and the levels of infiltrated immune cells. Significant increases in $\mathrm{CD} 163^{+}$macrophages 


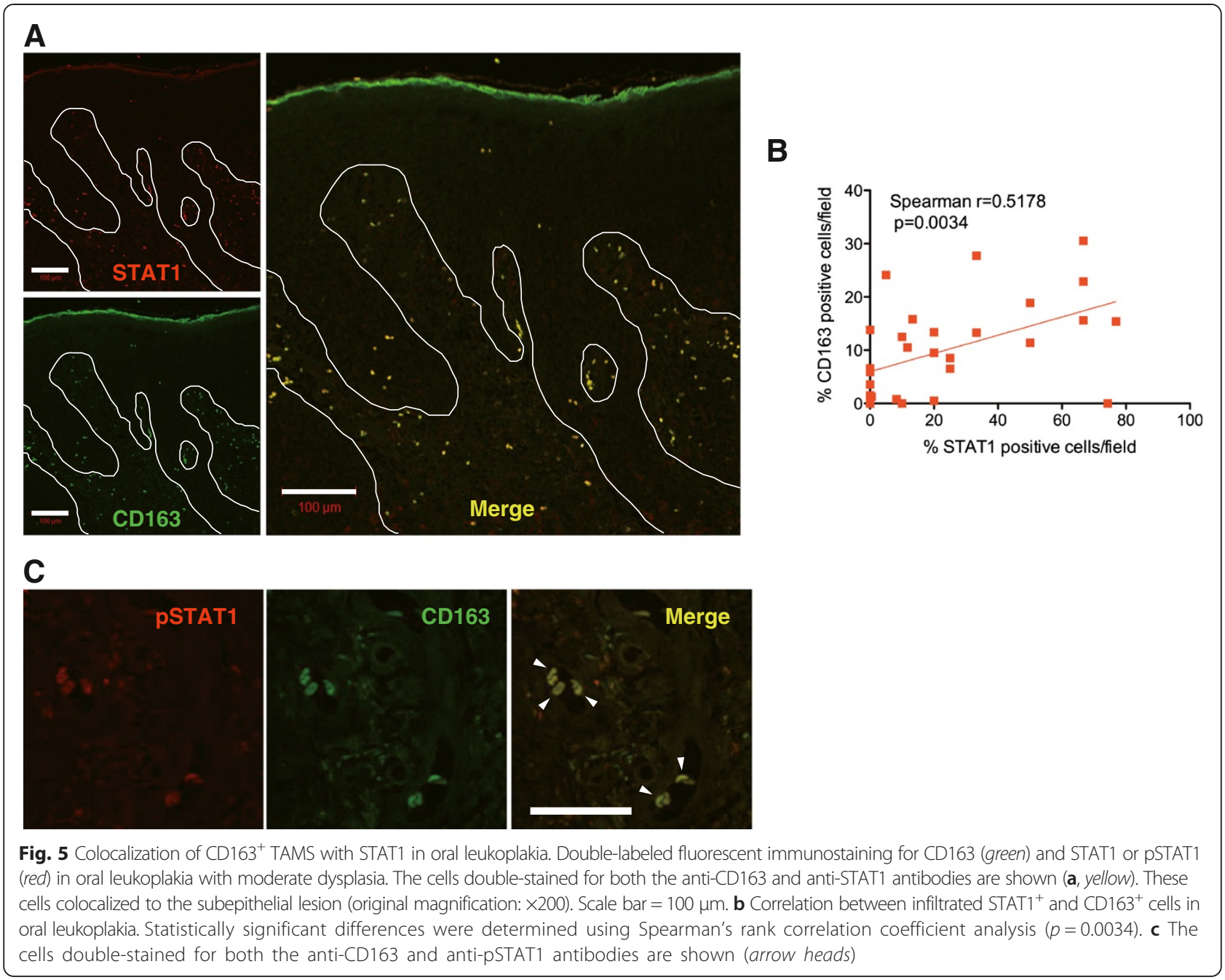

(Fig. 1) and intraepithelial $\mathrm{CD}^{+} \mathrm{T}$ cells (Fig. 2b) were observed in moderate dysplasia compared to samples without dysplasia (Fig. 1). The immunohistochemical analysis showed that $\mathrm{CD}_{163}{ }^{+}$macrophages were mainly distributed in the subepithelial region. Although the etiological roles of $\mathrm{CD} 163^{+}$macrophages and intraepithelial $\mathrm{CD}^{+}{ }^{+} \mathrm{T}$ cells in the development of dysplasia are unclear, $\mathrm{CD} 163^{+}$macrophages may contribute to the infiltration of intraepithelial $\mathrm{CD}_{4}^{+} \mathrm{T}$ cells. Because intraepithelial lymphocyte migration is accompanied by fragmentation of the basement membrane [57], $\mathrm{CD}_{163^{+}}$macrophages may secrete matrix metalloproteinases (MMPs) that degrade the basement membrane [58]. A loss of basement membrane components has been correlated with the invasive potential of malignant epithelial neoplasms [59]. CD163 ${ }^{+}$ macrophages and the infiltration of $\mathrm{T}$ cells into the epithelial lesion may contribute to the early architectural disturbance of the epithelium during the development of dysplasia.

\section{Conclusion}

In summary, we have identified an increase in CD163 ${ }^{+}$ macrophages in oral premalignant lesions and shown that $\mathrm{CD}_{163}{ }^{+}$macrophages coexpress STAT1, an M1related marker. Our results also suggest that recruited $\mathrm{CXCR}^{+}$and $\mathrm{CCR}^{+}$Th1 cells that produce IFN in the dysplastic lesion influence the polarization of the TAMs toward an M1 phenotype.

\section{Abbreviations}

TAMs: Tumor-associated macrophages; Th: helper T cells; CD: Cluster of differentiation; CXCR3: Chemokine (C-X-C motif) receptor 3;

CCR4: Chemokine (C-C motif) receptor 4; CXCL9: Chemokine (C-X-C motif) ligand 9; STAT1: Signal transducer and activator of transcription;

IFN: Interferon-; SCC: Squamous cell carcinoma; OSCC: Oral squamous cell carcinoma; CCL: Chemokine (C-C motif) ligand; IL: Interleukin; TNF-: tumor necrosis factor-; M1: Macrophage phenotype 1; M2: macrophage phenotype 2; BSA: Bovine serum albumin; PBS: Phosphate-buffered saline; TBS: Tris-HClbuffered saline; NO: Nitric oxide; VEGF: Vascular endothelial growth factor.

\section{Competing interest}

The authors declare that they have no competing interests. 


\section{Authors'contributions}

$\mathrm{KM}$ and $\mathrm{SH}$ participated in the collection of biopsy specimens and carried out the immunohistochemistry staining and quantification. $\mathrm{MH}$ carried out the double-immunofluorescence staining. JS performed statistical analyses. YO designed and coordinated the studies, participated in data analysis, and drafted the manuscript. All authors critically reviewed and accepted the fina version of the manuscript.

\section{Acknowledgments}

This work was supported by a Grant-in-Aid for Scientific Research.

\section{Author details}

'Division of Oral and Maxillofacial Surgery, Department of Diagnosis and Therapeutics Sciences, Meikai University of School of Dentistry, 1-1 Keyakidai, Sakado, Saitama 350-0283, Japan. ²Division of Microbiology and Immunology, Department of Oral Biology and Tissue Engineering, Meikai University of School of Dentistry, 1-1 Keyakidai, Sakado, Saitama 350-0283, Japan.

\section{Received: 9 December 2014 Accepted: 27 July 2015}

\section{Published online: 05 August 2015}

\section{References}

1. Jemal A, Bray F, Center MM, Ferlay J, Ward E, Forman D. Global cancer statistics. CA Cancer J Clin. 2011;61(2):69-90.

2. Howlader N, Ries LA, Mariotto AB, Reichman ME, Ruhl J, Cronin KA Improved estimates of cancer-specific survival rates from population-based data. J Natl Cancer Inst. 2010;102(20):1584-98.

3. Chin D, Boyle GM, Porceddu S, Theile DR, Parsons PG, Coman WB. Head and neck cancer: past, present and future. Expert Rev Anticancer Ther. 2006;6(7):1111-8

4. Gale N, Pich B, Sidransky D, Westra W, Califano J. Epithelial precusor lesions. In: Barnes L, Eveson J, Reichart P, Sidransky D, editors. Pathology and Genetics of Head and Neck Tumors. Lyon: IARCP press; 2005. p. 140-3.

5. Reibel J. Prognosis of oral pre-malignant lesions: significance of clinical, histopathological, and molecular biological characteristics. Crit Rev Oral Biol Med. 2003;14(1):47-62

6. Mao L. Leukoplakia: molecular understanding of pre-malignant lesions and implications for clinical management. Mol Med Today. 1997;3(10):442-8.

7. Mao L, Lee JS, Fan YH, Ro JY, Batsakis JG, Lippman S, et al. Frequent microsatellite alterations at chromosomes 9p21 and 3p14 in oral premalignant lesions and their value in cancer risk assessment. Nat Med. 1996;2(6):682-5

8. Papadimitrakopoulou V, Izzo J, Lippman SM, Lee JS, Fan YH, Clayman G, et al. Frequent inactivation of p16INK4a in oral premalignant lesions. Oncogene. 1997:14(15):1799-803.

9. Coussens LM, Werb Z. Inflammation and cancer. Nature. 2002:420(6917):860-7.

10. Mantovani A, Allavena P, Sica A, Balkwill F. Cancer-related inflammation. Nature. 2008;454(7203):436-44

11. Bingle L, Brown NJ, Lewis CE. The role of tumour-associated macrophages in tumour progression: implications for new anticancer therapies. J Pathol. 2002:196(3):254-65.

12. Mantovani A, Sozzani S, Locati M, Allavena P, Sica A. Macrophage polarization: tumor-associated macrophages as a paradigm for polarized M2 mononuclear phagocytes. Trends Immunol. 2002;23(11):549-55.

13. Pollard JW. Tumour-educated macrophages promote tumour progression and metastasis. Nat Rev Cancer. 2004:4(1):71-8.

14. Forssell J, Oberg A, Henriksson ML, Stenling R, Jung A, Palmqvist R. High macrophage infiltration along the tumor front correlates with improved survival in colon cancer. Clin Cancer Res. 2007;13(5):1472-9.

15. Zhou Q, Peng RQ, Wu XJ, Xia Q, Hou JH, Ding Y, et al. The density of macrophages in the invasive front is inversely correlated to liver metastasis in colon cancer. J Transl Med. 2010:8:13.

16. Kawai O, Ishii G, Kubota K, Murata Y, Naito Y, Mizuno T, et al. Predominant infiltration of macrophages and CD8(+) T Cells in cancer nests is a significant predictor of survival in stage IV nonsmall cell lung cancer. Cancer. 2008:113(6):1387-95.

17. Ohri CM, Shikotra A, Green RH, Waller DA, Bradding P. Macrophages within NSCLC tumour islets are predominantly of a cytotoxic M1 phenotype associated with extended survival. Eur Respir J. 2009;33(1):118-26.
18. Ma J, Liu L, Che G, Yu N, Dai F, You Z. The M1 form of tumor-associated macrophages in non-small cell lung cancer is positively associated with survival time. BMC Cancer. 2010;10:112.

19. Gordon S. Alternative activation of macrophages. Nat Rev Immunol. 2003;3(1):23-35

20. Migliorati CA, Migliorati EK, Silverman Jr S, Greenspan D, Greenspan JS Phenotypic identification of mononuclear cells in oral premalignant lesions and cancer by monoclonal antibodies. J Oral Pathol. 1986;15(6):352-8.

21. Eskinazi DP, Perna JJ, Mihail R. Mononuclear cell subsets in patients with oral cancer. Cancer. 1987;60(3):376-81.

22. Ogawa Y, Maeda T, Seguchi H, Yoshida S, Inomata T, Hamada F, et al. Immunohistochemical study of mononuclear cell infiltrates in squamous cell carcinoma of oral cavity and paranasal sinus. Oncology. 1987:44(4):219-23.

23. Hirota J, Ueta E, Osaki T, Ogawa Y. Immunohistologic study of mononuclear cell infiltrates in oral squamous cell carcinomas. Head Neck. 1990;12(2):118-25.

24. Gannot G, Gannot I, Vered H, Buchner A, Keisari Y. Increase in immune cell infiltration with progression of oral epithelium from hyperkeratosis to dysplasia and carcinoma. Br J Cancer. 2002;86(9):1444-8

25. Li C, Shintani S, Terakado N, Nakashiro K, Hamakawa H. Infiltration of tumor-associated macrophages in human oral squamous cell carcinoma. Oncol Rep. 2002:9(6):1219-23.

26. El-Rouby DH. Association of macrophages with angiogenesis in oral verrucous and squamous cell carcinomas. J Oral Pathol Med. 2010;39(7):559-64.

27. Mori K, Hiroi M, Shimada J, Ohmori Y. Infiltration of M2 tumor-associated macrophages in oral squamous cell carcinoma correlates with tumor malignancy. Cancers. 2011;3(4):3726-39.

28. Fujii N, Shomori K, Shiomi T, Nakabayashi M, Takeda C, Ryoke K, et al. Cancer-associated fibroblasts and CD163-positive macrophages in oral squamous cell carcinoma: their clinicopathological and prognostic significance. J Oral Pathol Med. 2012;41(6):444-51.

29. Costa NL, Valadares MC, Souza PP, Mendonca EF, Oliveira JC, Silva TA, et al Tumor-associated macrophages and the profile of inflammatory cytokines in oral squamous cell carcinoma. Oral Oncol. 2013:49(3):216-23.

30. Barnes L, Eveson J, Reichart P, Sidransky D. Pathology and Genetics of Head and Neck Tumours. Lyon: IARC press; 2005

31. Falini B, Flenghi L, Pileri S, Gambacorta M, Bigerna B, Durkop H, et al. PG-M1: a new monoclonal antibody directed against a fixative-resistant epitope on the macrophage-restricted form of the CD68 molecule. Am J Pathol. 1993;142(5):1359-72.

32. Badylak SF, Valentin JE, Ravindra AK, McCabe GP, Stewart-Akers AM. Macrophage phenotype as a determinant of biologic scaffold remodeling. Tissue Eng Part A. 2008;14(11):1835-42.

33. Lau SK, Chu PG, Weiss LM. CD163: a specific marker of macrophages in paraffin-embedded tissue samples. Am J Clin Pathol. 2004;122(5):794-801.

34. Bonecchi R, Bianchi G, Bordignon PP, D'Ambrosio D, Lang R, Borsatti A, et al. Differential expression of chemokine receptors and chemotactic responsiveness of type $1 \mathrm{~T}$ helper cells (Th1s) and Th2s. J Exp Med. 1998:187(1):129-34.

35. Lehtonen A, Matikainen S, Julkunen I. Interferons up-regulate STAT1, STAT2, and IRF family transcription factor gene expression in human peripheral blood mononuclear cells and macrophages. J Immunol. 1997;159(2):794-803.

36. Liao F, Rabin RL, Yannelli JR, Koniaris LG, Vanguri P, Farber JM. Human Mig chemokine: biochemical and functional characterization. J Exp Med. 1995;182(5):1301-14

37. Qian BZ, Pollard JW. Macrophage diversity enhances tumor progression and metastasis. Cell. 2010;141(1):39-51.

38. Komohara Y, Ohnishi K, Kuratsu J, Takeya M. Possible involvement of the M2 anti-inflammatory macrophage phenotype in growth of human gliomas. J Pathol. 2008;216(1):15-24

39. van Dongen $M$, Savage ND, Jordanova ES, Briaire-de Bruijn $H_{\text {, Walburg KV, }}$ Ottenhoff TH, et al. Anti-inflammatory M2 type macrophages characterize metastasized and tyrosine kinase inhibitor-treated gastrointestinal stromal tumors. Int J Cancer. 2010;127(4):899-909.

40. Zhang B, Yao G, Zhang Y, Gao J, Yang B, Rao Z. M2-polarized tumor-associated macrophages are associated with poor prognoses resulting from accelerated lymphangiogenesis in lung adenocarcinoma. Clinics (Sao Paulo). 2011;66(11):1879-86.

41. Kurahara H, Takao S, Maemura K, Mataki Y, Kuwahata T, Maeda K, et al. M2polarized tumor-associated macrophage infiltration of regional lymph nodes 
is associated with nodal lymphangiogenesis and occult nodal involvement in pN0 pancreatic cancer. Pancreas. 2013;42(1):155-9.

42. Stein M, Keshav S, Harris N, Gordon S. Interleukin 4 potently enhances murine macrophage mannose receptor activity: a marker of alternative immunologic macrophage activation. J Exp Med. 1992;176(1):287-92.

43. Pettersen JS, Fuentes-Duculan J, Suarez-Farinas M, Pierson KC, Pitts-Kiefer A, Fan L, et al. Tumor-associated macrophages in the cutaneous SCC microenvironment are heterogeneously activated. J Invest Dermatol. 2011;131(6):1322-30.

44. He KF, Zhang L, Huang CF, Ma SR, Wang YF, Wang WM, et al. CD163+ tumor-associated macrophages correlated with poor prognosis and cancer stem cells in oral squamous cell carcinoma. BioMed research international. 2014;2014:838632

45. Wang S, Sun M, Gu C, Wang X, Chen D, Zhao E, et al. Expression of CD163, interleukin-10, and interferon-gamma in oral squamous cell carcinoma: mutual relationships and prognostic implications. Eur J Oral Sci. 2014;122(3):202-9.

46. Biswas SK, Mantovani A. Macrophage plasticity and interaction with lymphocyte subsets: cancer as a paradigm. Nat Immunol. 2010;11(10):889-96.

47. DeNardo DG, Barreto JB, Andreu P, Vasquez L, Tawfik D, Kolhatkar N, et al. CD4(+) T cells regulate pulmonary metastasis of mammary carcinomas by enhancing protumor properties of macrophages. Cancer Cell. 2009;16(2):91-102.

48. Ohtaki Y, Ishii G, Nagai K, Ashimine S, Kuwata T, Hishida T, et al. Stromal macrophage expressing CD204 is associated with tumor aggressiveness in lung adenocarcinoma. J Thorac Oncol. 2010;5(10):1507-15.

49. Loetscher M, Gerber B, Loetscher P, Jones SA, Piali L, Clark-Lewis I, et al. Chemokine receptor specific for IP10 and mig: structure, function, and expression in activated T-lymphocytes. J Exp Med. 1996;184(3):963-9.

50. Ohmori Y, Hamilton TA. Cell type and stimulus specific regulation of chemokine gene expression. Biochem Biophys Res Commun. 1994;198(2):590-6.

51. Hiroi $\mathrm{M}, \mathrm{O}$ mori $\mathrm{Y}$. Constitutive nuclear factor $\mathrm{KB}$ activity is required to elicit interferon-gamma-induced expression of chemokine CXC ligand 9 (CXCL9) and CXCL10 in human tumour cell lines. Biochem J. 2003;376(Pt 2):393-402.

52. Ohmori Y, Hamilton TA. The interferon-stimulated response element and a $\mathrm{KB}$ site mediate synergistic induction of murine IP-10 gene transcription by IFN- $\gamma$ and TNF-a. J Immunol. 1995;154(10):5235-44.

53. Altenburg A, Baldus SE, Smola H, Pfister H, Hess S. CD40 ligand-CD40 interaction induces chemokines in cervical carcinoma cells in synergism with IFN- $\gamma$. J Immunol. 1999;162(7):4140-7.

54. Chi LM, Lee CW, Chang KP, Hao SP, Lee HM, Liang Y, et al. Enhanced interferon signaling pathway in oral cancer revealed by quantitative proteome analysis of microdissected specimens using 160/180 labeling and integrated two-dimensional LC-ESI-MALDI tandem MS. Mol Cell Proteomics. 2009;8(7):1453-74.

55. Dunn GP, Koebel CM, Schreiber RD. Interferons, immunity and cancer immunoediting. Nat Rev Immunol. 2006;6(11):836-48.

56. O'Sullivan T, Saddawi-Konefka R, Vermi W, Koebel CM, Arthur C, White JM, et al. Cancer immunoediting by the innate immune system in the absence of adaptive immunity. J Exp Med. 2012;209(10):1869-82.

57. Uccini S, Ruco LP, Monardo F, La Parola IL, Cerimele D, Baroni CD. Molecular mechanisms involved in intraepithelial lymphocyte migration: a comparative study in skin and tonsil. J Pathol. 1993;169(4):413-9.

58. Hanania R, Sun HS, Xu K, Pustylnik S, Jeganathan S, Harrison RE. Classically activated macrophages use stable microtubules for matrix metalloproteinase-9 (MMP-9) secretion. J Biol Chem. 2012;287(11):8468-83.

59. Tosios Kl, Kapranos N, Papanicolaou SI. Loss of basement membrane components laminin and type IV collagen parallels the progression of oral epithelial neoplasia. Histopathology. 1998;33(3):261-8.

\section{Submit your next manuscript to BioMed Central and take full advantage of:}

- Convenient online submission

- Thorough peer review

- No space constraints or color figure charges

- Immediate publication on acceptance

- Inclusion in PubMed, CAS, Scopus and Google Scholar

- Research which is freely available for redistribution

Submit your manuscript at www.biomedcentral.com/submit 